\title{
From Handpress to Handheld: Rare Book and Special Collections Libraries forming the \#LibrariesOfInstagram
}

\author{
Jillian Sparks \\ St. Olaf College \\ sparks2@stolaf.edu
}

\author{
Kimberley Bell \\ Queen's University \\ kim.bell@queensu.ca
}

\author{
Alvan Bregman \\ University of Illinois at \\ Urbana Champaign (Emeritus) \\ ambregman@illinois.edu
}

\begin{abstract}
This paper addresses how Instagram serves as a platform to engage a community of librarians, researchers, and bibliophiles. There is a relative lack of research on Instagram and communities of this kind. Focusing on the development of the Libraries of Instagram community, we consider the importance of hashtag campaigns in generating a community space. The paper also comments on the way the emblematic nature of Instagram posts resonates with the rare book and special collections community. The case of @Jordan_Library, the Instagram account of a Canadian rare book and special collections library, exemplifies the Libraries of Instagram community and the use of Instagram to build community across the cultural heritage sector and beyond.
\end{abstract}

\section{Introduction}

Like many organizations, libraries and other cultural heritage institutions increasingly use social media as a way to communicate with stakeholders and promote their message. The collaborative and interactive nature of social media opens up "avenues for community building and relationship marketing" [13] that have been widely adopted: a 2014 report found that over 70 percent of libraries use social media tools with 30 percent of librarians posting daily [25]. By establishing a social media presence, libraries operate under the belief that they will reach their users where they are already communicating and be able to integrate the library into the local community. However, the expected connection to the community does not always come to fruition.

Social media provides a cheap opportunity to market the library, but, as Jones and Harvey [21] found with academic libraries, users (in this case students) do not generally want to engage with the library in their personal feeds. Instead, they want to draw a line between personal life and academic or work life. By only promoting events and services, libraries struggle to engage their followers on social media. Still, libraries do see social media as an effective tool for building "community with ... users and also with other institutions and industry contacts" [25, p. 5]. Community building and increasing the network of supporters are goals of great importance to cultural heritage institutions since digital advances have put stress on the preservation, curation and educational use of material objects (including printed books).

This paper discusses the development of \#LibrariesOfInstagram, a virtual community of rare book and special collections libraries, researchers, students, antiquarian booksellers and bibliophiles. The paper outlines the processes involved in forming and promoting this online community, and the way the attributes of the platform and structural elements of Instagram posts resonate with library professional practice. The paper reflects on experiences at the W.D. Jordan Rare Books and Special Collections and its Instagram account.

\section{Network building in the Rare Book and Special Collections Community}

Rare books and special collections can be found in many institutions, notably libraries, archives, and museums. Often the items in these collections are unique, or distinguished by age, association with a collector, type of material, or variants in editions. However, items associated with particular events, authors, publishers, or collectors can be spread across many sites as a result of the collecting habits of the institution, the availability of items for acquisition, and donor contributions. Scholarly work in the area centers on the direct examination of individual artifacts, only a tiny fraction of which are ever placed on exhibit. The exact holdings of many collections and sites are not well known, either to other institutions or to potential researchers, despite the best efforts of catalogers and registrars. This has led to an increased importance of outreach, the processing of "hidden collections" and 
promoting the use of primary materials in teaching and research, in keeping with institutional responsibility to facilitate public access and to disseminate knowledge. In this endeavor, many institutions have turned to social media as an outreach mechanism.

The case of \#LibrariesOfInstagram exemplifies this trend and presents a particular success story about how Instagram resonated with and supported the creation of a virtual community for the rare book and special collections community. Of note is the way separate Instagram accounts, started as outreach from individual libraries, have brought institutions and a wide range of individuals together based on professional practice and personal interest. Both social and technical features support this success: social, in the way connecting across institutions, collections, and roles (librarians, researchers, book dealers, faculty, and students) addresses professional goals; and technical, in the way features of Instagram, notably the combination of image and text, resonate with the professional focus and practice of the rare book and special collections community.

Evaluation of the history and practice of participation in \#LibrariesOfInstagram reveals how the adoption of Instagram extends and supports the existing rare book and special collections community while also becoming its own community of practice [38]. As described for other virtual communities, coorientation to a wider interest can be a key motivator for those not (yet) heavily embedded in the community, allowing observation and learning around a personal or career interest $[3 ; 12 ; 23 ; 29 ; 36]$.

Coorientation to book culture, book arts, and librarianship acts as an overall motivator for following and participating in \#LibrariesOfInstagram. Configurations of such social networks require strongly engaged central actors who maintain a commitment to the operation of the site, as can be found in the professional librarian engagement in \#LibrariesOfInstagram. Such networks thrive when peripheral and new actors can begin to engage, building their weak tie connection to the site into stronger, more multi-faceted connection to the virtual community, e.g., from following, to liking, to commenting, to posting [9]. Moreover, \#LibrariesOfInstagram can now serve as a latent tie structure, a technical platform which brings together those who do not (yet) know each other, providing a means to share interests, and providing the potential for turning latent ties into weak and then strong ties $[10 ; 11]$. An example of this can be seen in the fact-toface "meet-ups" that happen based on an online connection, as is now the case for \#LibrariesOfInstagram as described below.

While the network is built through the connectivity Instagram affords, technical features of
Instagram resonate with the professional focus and practice of rare book and special collections community. Images of book covers may be playfully posted in response to hashtag challenges (e.g., \#TinyTuesday, \#PublishersBindingThursday), but accompanying text both informs and identifies the source in keeping with the librarians' practice. The openness of the platform is another feature that resonates with this community, providing education and outreach to distributed professional practitioners, non-institutionally affiliated collectors, book dealers, bibliophiles, students, and library users.

Two further effects of social networking through \#LibrariesOfInstagram are the way this connects holdings and institutions. Each hashtag brings distributed collections together virtually, creating and exhibiting the connection between sites. And, each institutional poster also exhibits their collection, something otherwise difficult to achieve without site visits and individual access to holdings. Again, these outcomes resonate with the professional community in supporting goals of scholarship and outreach relating to their collections.

\section{Social Media Use by Libraries}

Library and archival literature has a wide coverage of how libraries can and should use social media platforms such as Facebook and Twitter to market library events and services, but much less on Instagram or on the use of social media for community building. The idea has been that "[i]nformation dissemination is the primary goal of any Twitter program run by the library" [33], focusing the use of social media in library orientation, for example, to promotion rather than to engaging users. While it is important to share knowledge of what is in a collection, passive sharing is not the same as engaging and adding new members to the community of those passionate, knowledgeable or even curious about rare books and special collections.

Marketing literature includes overviews of how to start up a social media presence and keep it going (with an emphasis on Facebook) [34]; and how to go beyond event and services announcements to providing online content that matters to patrons [35]. Similarly, best practice and marketing strategy guides have been created to introduce social media to archives and special collections with examples of how to promote collections online [37]. Studies on the effectiveness of this promotion report on traffic to their online finding aids and website, but do not consider how users interact with their online content [39].

There are few articles published in scholarly journals on how rare book and special collections 
libraries use Instagram. Dean and Grovers [4] is an example, continuing the theme of using social media to convey information and promote collections and discussing how undergraduate students learn how to physically "read" a rare book by researching materials for Instagram posts.

More information on community practice and how special collections libraries use Instagram can be found in institutional blogs and on personal professional websites. In 2017, Dean published in Medium, "Special Collections Instagram Syllabus," a list compiling top accounts and tips articles, conference presentations, and a few published articles. Collaborators Lauren Hewes, American Antiquarian Society; Jay Sylvestre, University of Miami; Diane Dias De Fazio, New York Public Library; and Jason W. Dean, Southwestern University, shared the list before their talk at the 2017 Rare Books and Manuscript Section Conference [5]. These resources emphasize the same tips for success: post interesting items, interact with followers and participate in community campaigns [31].

Garner, Goldberg and Pou's case study on \#ColorOurCollections [7], a social media campaign initiated by the New York Academy of Medicine Library that ran from February 1 to 5, 2016, demonstrates how to run a successful community campaign. Their article lays out the goals and methodology for their campaign stating, "[w]e knew from the beginning that the success of \#ColorOurCollections would depend on the participation of other libraries and museums. By extending an invitation to our peers, we aimed to establish long-term relationships with potential for further online collaboration and partnership" [7, p. 102]. During the five days, over 200 institutions shared coloring books or pages, allowing people to engage with their collections in an interactive way while simultaneously providing access to "material that may be known only to a well-connected research" [7, p. 116]. The New York Academy of Medicine Library continued to sponsor the campaign with 115 institutions participating in 2019 [27].

The Libraries of Instagram community was built through a long series of hashtag campaigns similar to \#ColorOurCollections. The interactive nature of these challenges lends itself to collaboration. That this collaboration leads to real-life connections is what makes Instagram an important platform for community building.

\section{Instagram and The Libraries of Instagram}

Instagram was launched in October 2010 and has become one of the largest social media platforms with over one billion active monthly users [17]. It began as a simple way to share and quickly edit photos with filters and has evolved to include video sharing (60 seconds), IGTV (up to 10 minutes), direct messaging, and Instagram stories (images or videos that disappear after 24 hours).

Unlike Twitter, which can have text-only posts with a word limit, Instagram requires that a photo or video be included with each post. Beginning in May 2019, users can now use the 'create' and 'camera' mode in Instagram stories. This new camera design allows users to create a story post without a photo or video, by using tools like effects and interactive stickers [15]. Although Laestadius [22] in the article, "Instagram" suggests that Instagram encourages the use of filters over skillful photography, this is not the case in the rare book community. Filters are not used or rarely used in the library online community as the intent is to present items as they are. Misrepresenting objects could have adverse outcomes for the institution and the researcher.

In addition to visual presence, hashtags form an essential part of the platform, set at a limit of thirty hashtags per post. Instagram did not originally have a set number of allowed hashtags per post, limiting it later. Users initially circumvented the limit by posting the hashtags as comments until Instagram stopped the practice [19]. The purpose of hashtags in Instagram initially used on the Twitter platform in 2007, is to build communities of people with similar interests [28]. The comments also serve as building blocks for community interaction. Whereas Twitter serves as a conversation, or "thread," Instagram connects through hashtags and comments.

Through the hashtags and comments, rare book and special collections libraries have created an international community of interest that is not limited to institutions but crosses the industry to include rare book dealers, private collectors, and bibliophiles in general.

\subsection{Hashtag Challenges and Instameets}

The Libraries of Instagram community is largely spearheaded by rare book and special collections libraries and was created through monthly challenges posed by one library to another. The hashtag challenges are sponsored by one institution or individual and ask members to share books or other heritage material related to a theme (these generally 
occur on Wednesdays). Diane Dias De Fazio, founder of @IGLibraries (2016), writes "[t]he first \#LibrariesOfInstagram 'challenge' was posed by @um_spec_coll [University of Miami Special Collections] to @sfplbookarts [San Francisco Public Library Book Arts \& Special Collections] in February 2015, and the community has never looked back. Open themes have included publishers' bookbindings, boats, and dogs; the spirit of a challenge is to encourage everyone to participate, from the armchair Instagrammer to the Ivy League collection" [6]. The open nature of the challenges enables multiple institutions or bibliophiles to participate. Active participants include libraries, archives, book dealers, and private collectors.

Consistently posing challenges has led the Libraries of Instagram to organize more formally. As Serafinelli asserts, "Instagram users can be clustered into two groups: general users and members of the Instagram community (Igers). In addition, the Igers presents an internal subdivision that sees the participants divided into Igers community members and managers" [32, p. 88].

The task of managing was initially coordinated solely through the direct message feature on Instagram. However, messages are capped at fifteen members. In response, Dias De Fazio founded IGLibraries. According to their website (https://iglibraries.org/), “\#igLibraries is a community of users who represent, work in, or are fans and friends of libraries - an international group highlighting rare books, special and manuscript collections, circulating, mobile, and public libraries, featuring booksellers, students, museums, cultural organizations, colleges and universities, and independent professionals".

People submit their photos to be posted to the IGLibraries website or use the hashtags \#iglibraries and \#ig_libraries to have their images shared on the IGLibraries Instagram account. These two hashtags serve as a connection to the community furthering the goal, "to bring people together, share content and ideas, and to celebrate primary resources on social media". The account has over 2,000 followers and more than 30,000 posts with the hashtag, \#iglibraries. The tag, \#LibrariesOfInstagram has close to 500,000 posts, but does not receive the same community moderation. Instead, it is used widely by libraries and people who love and share images of libraries and library content. To keep the IGLibraries community consistent, IGLibraries created a freely accessible Hashtag Library to provide a list of past and current challenges and other frequently used community tags [14]. The Hashtag Library enables those not privy to the direct message, to view upcoming challenges and to adopt common tags.
As a result of the challenges and established community, members have moved their interactions offline to "real life" meet-ups or InstaMeets, typically at the RBMS annual conference. Serafinelli defines an InstaMeet as a "meet-up that sees the Igers community members meeting and taking photographs together" [32, p. 93]. At an InstaMeet, participants share best practices, introduce new users to the platform, and take photos of rare books together. The shared experience is documented across accounts.

The communal outreach goal of promoting rare materials makes the IGLibraries community unique. They do not solely market library events or services, but engage with other institutions or individuals over a mutual interest in the materiality of the book, encouraging people to seek out contact with rare books either physically or virtually.

The community also expresses solidarity with its members, for example in the case of comments of sympathy and support for @annielauriesbooks: a private collector who lost their home and subsequently, their rare book and ephemera collection in the Paradise, California fire of November 2018.

\section{Emblems and the Anatomy of Posts}

One of the reasons the IGLibraries community continues to grow in popularity is the content of the posts. Like museums, rare book and special collections libraries hold objects that are interesting to photograph and describe. There is no legislation that defines a good post, and criteria will vary among posting communities, however defined. In the IGLibraries community, a good post has an eye-catching image that will be supported by a short but accurate and informative text. The addition of appropriate hashtags may extend or narrow the intended audience or do both. IGLibraries posts rarely make use of one of the defining features of Instagram, namely its image filters. Posts aim to present original materials without distortion-colors should be as natural as possible; resolution should be sharp, images should be clear.

One attraction of Instagram within a rare book context may be that the post structure is reminiscent of an early modern literary genre, the emblem. An emblem has a three-part structure: Motto (caption or title), Picture, and Text [26]. All three parts were generally necessary for the resulting form to be called an emblem. (By contrast, for example, a composition consisting only of a Motto and a Picture but lacking a Text, was defined as a "device" or impresa.) The three parts of an emblem are equivalent to the basic components of an Instagram post, which consist of Hashtags (motto), Picture, and Text. Emblems were issued in collections, called emblem books, and the 
more popular collections often were issued with commentaries, just as popular Instagram posts tend to generate comments.

We introduce the term "emblem" in a technical sense to reduce confusion: on Instagram, the terms "emblem" and "logo" are constantly confused; the word "emblem" is also commonly linked to badge or tattoo designs, and trademarks. We suggest here reading each post as a new emblem with three parts: image, caption, and hashtags.

Emblem collections were popular for about 200 years, from the publication of the first emblem book by Andrea Alciato in 1531 [1] to the first half of the $18^{\text {th }}$ century. Along the way, collections might be created to focus on single sub-genres, for example, emblems of love, or religious emblems; or they might be created to celebrate notable civic events, such as the coronation of a monarch, the birth of a royal heir, or a royal entrance or festival. Similarly, using hashtag challenges and responding to current events, IGLibraries post content that can be grouped by genre (i.e. \#MiniatureMonday, \#ForeedgeFriday, \#HatsInTheLibrary, etc.)

The relationship of picture to text in emblems was often seen in terms of the ancient critical precept of $u t$ pictura poesis, by which a picture is a kind of silent poem, and a poem a kind of speaking picture. The English emblematist Henry Hawkins was explicit about this in his collection The Devout Heart (1634) admonishing the reader to "eye well and mark these silent poesies, give ear to these speaking pictures" [8, p. 386]. In the rare book and special collections community, it is important to give as much consideration to the text as to the image, for the two reinforce and indeed interpret each other for the viewer. And to stretch similarities even further, we can also appreciate how Instagram images are understood by people speaking different languages, and how technology can verbalize content for unsighted persons.

Emblem images were limited by the size of the woodblock or plate and the amount of space on the page which affected how they were printed. Similarly, Instagram's square frame limits a post's composition. Serafinelli explains, "[ $\mathrm{t}]$ he use of a square frame guides users to think of the images in relation to the frame, which consequently changes the rules of composition. It means that forms and objects need to be located in the photo in relation to the frame. Even if the photo can now be adapted into a rectangular shape inside the square frame, users are still influenced by the square frame" [32: 70-71]. The influence of the square frame is seen in the types of images produced by libraries. Photos of details, books on a shelf, the physical spaces, or what you can hold in your hand dominate the types of images shared. Even if rectangular images are posted because they appear as a square in an account feed, a tendency persists to photograph material to fit the square.

Captions range in length and tone. Keeping in line with the goals of promotion and education, institutional accounts include informative captions that describe the object and contextualize why the image was shared. Best practice encourages libraries to share shelfmarks (call numbers) or publication information for the item enabling viewers to find the book on their own if they choose to see it at the library. Generally, photographs are shared because the account manager had a personal reaction to the book or object. This emotional connection relates to the material shared, but also "[a] general interest and expectation of positivity emerges by the use of Instagram. [...] Photosharing, in fact, seems be [sic] motivated by the presence of a positive mood or particular emotions that come with images" [32, p. 59-60].

\section{Assessing Participation in \#Libraries of Instagram}

The IGLibraries community includes hundreds of rare book and special collections libraries, booksellers, conservators, archives, and posting bibliophiles, and many thousands of their followers. As of April 2018, the Special Collections + Social Media Wiki, a community moderated list of special collections social media sites, included 87 libraries with Instagram accounts [20]. Not all rare book libraries using Instagram appear on this list, but it does provide a sense of how many institutions use Instagram across North America.

With such a large community, collecting data from a minimum of 87 libraries presents challenges. In her article, Laestadius outlines several approaches for collecting and analyzing Instagram data. She notes that small sample sizes "currently offer the best opportunity to make sense of Instagram post components as a unit, rather than considering images/ videos, hashtags, captions, comments and likes independently" [22, p. 581]. Because the image and text are contextually linked, to analyze them separately does not make sense. However, counts on hashtags, like the monthly hashtag challenges, provides valuable information when looking at how many users participate in the challenge. Thus, to capture how members participate in the IGLibraries community, we have focused on the account @Jordan_Library (W.D. Jordan Rare Books and Special Collections).

The data for this study has been taken directly from the Instagram app, which provides information from a daily perspective up to a two-year evaluation. 
The more likes that a post receives, the wider the reach. In 2016, Instagram changed its algorithm, ending the reverse-chronological feed and replacing it with one that prioritized "the moments you care about" [18]. Three years later, as shown in Figure 1, on January 22, 2019, in response to criticism, Instagram announced on Twitter that they had not made any recent changes to feed ranking and that the activity of an account is what determines engagement. In a nutshell, the more likes and comments that a post receives, the wider the reach.

In January of 2016, W.D. Jordan Rare Books and Special Collections at Queen's University, Kingston, Ontario, created an Instagram account (@Jordan_Library), having established a Twitter account the previous year. By April of the same year, the account had 500 followers, double the number of followers on Twitter. The Instagram account was clearly connecting with more followers, but they were not coming from the local community. On the contrary, @Jordan_Library had tapped into an international community of book lovers and the Libraries of Instagram community. Three years later, Jordan_Library has over eight thousand followers.

All Instagram posts are issued simultaneously on Twitter, which sometimes yields double results. For example, the Jordan_Library post on March 5, 2019, featured a book cover displaying the seal of the Signet Library, the repository of the Society of Writers to Her Majesty's Signet of Edinburgh. This post received only 184 likes on Instagram with no comments. However, on Twitter the same post resulted in an enthusiastic and informative conversation thread consisting of six posts from the Signet Library itself. This example helps typify the difference between Instagram and Twitter posts, the latter more readily lending themselves to conversation threads.

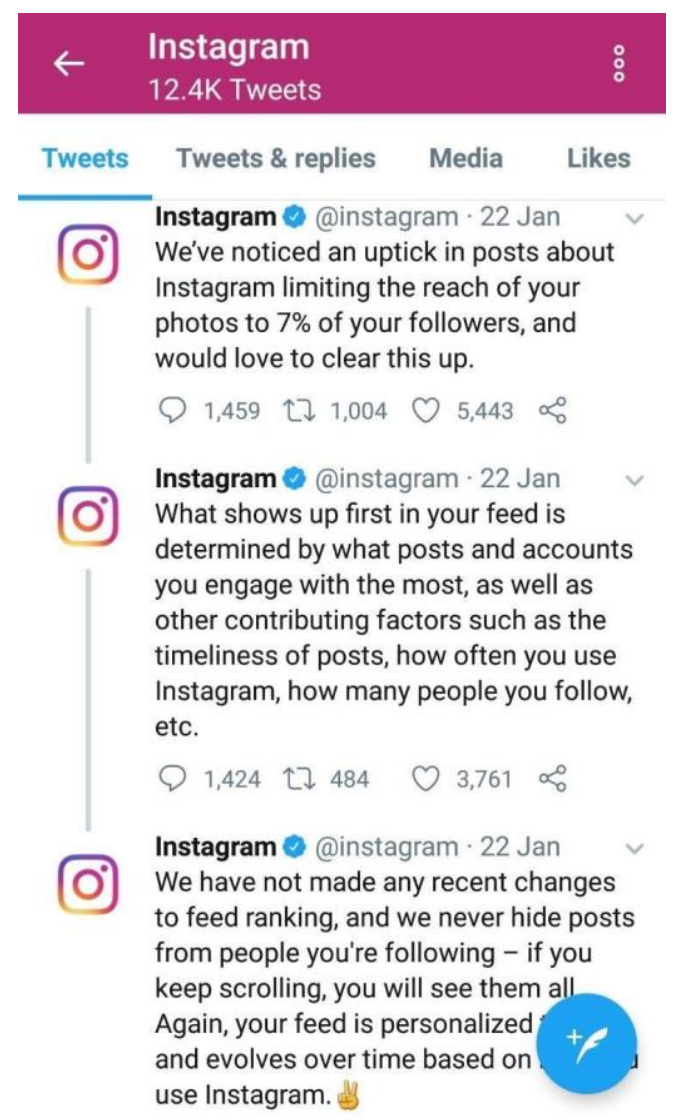

Figure 1: Tweets from Instagram on January 22, 2019

\subsection{Functional change}

The functionality of Instagram is constantly changing, responding to user needs, with additions of filters, videos, stories, and in November 2018, adding automatic alternative text making the platform more accessible to people with visual impairments [9]. Not all changes, however, end up in the best interests of communities. In April of 2019, Instagram began hiding the number of likes as part of a pilot project in Canada. The person creating the post can still see the number of likes, but followers cannot. The likes do not show up automatically, the user needs to tap "others" in the feed to get the number. It is entirely possible to determine the number of likes that other posts get, as Mark Zuckerberg explained "You can see who liked a photo or video, you can tap through to see [the list], and if you have the time you can add them all up yourself' [24].

In our case, and for accounts similar to ours, we cannot sacrifice the staff time needed to add up the likes on other pages. Likes have provided a certain amount of social capital, especially for accounts such as Jordan_Library's, where time spent curating the feed must relate positively to the account's 
engagement with followers. The developers claim that eliminating like counts will provide users with a more holistic approach, one in which the poster has more freedom to create content that is not tied exclusively to the number of likes a post receives. However, it negatively affects the ability for nonprofits to show use and thus value for outreach activities.

The initial outcome of this change for Jordan_Library, was a drop in the number of likes on posts, although, without a study in place, it could be argued that other factors contributed to this decrease. Posts that have a more significant number of likes, especially in a short period, seem to encourage the user to stop scrolling and take a more extended look, "nothing draws a crowd like a crowd" [2]. Part of building community engagement, especially within the libraries of Instagram community, is to know what works and what does not, not only for the institution's feed, but for others in the community. If engaging in monthly challenges does not net a comparable number of likes, what can or should be adjusted for future posts? If likes are the simplest and most readily understood metric of success, how else is success to be measured?

With the amount of engagement hidden, it will be impossible to know how the account compares to similar accounts. This does not reflect a simple need for validation, but an opportunity to take a more indepth look at engagement if posts are not measuring up. It is unclear how such a change will protect the user, but it may pave the way for paid advertisements.

\subsection{Statistics}

Briefly, this is a snapshot of how users share, view or engage with Jordan's content and profile.

As shown in Figures 2 and 3, the Jordan account has a following that is $57 \%$ women, and most followers $(62 \%)$ are $25-44$ years of age. IGLibraries challenges do not generally result in many likes but do tend to generate comments, if only from the sponsoring account. Followers prefer old, or old looking books, and there was considerable engagement with an image of Notre Dame, posted during the recent fire at the Cathedral.

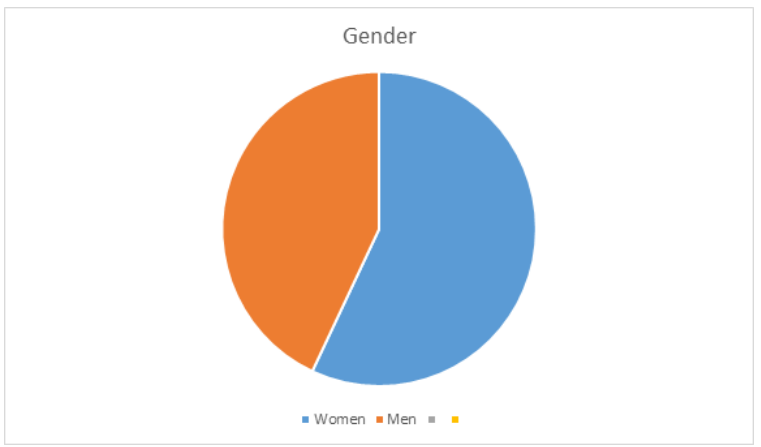

Figure 2: Gender breakdown of followers

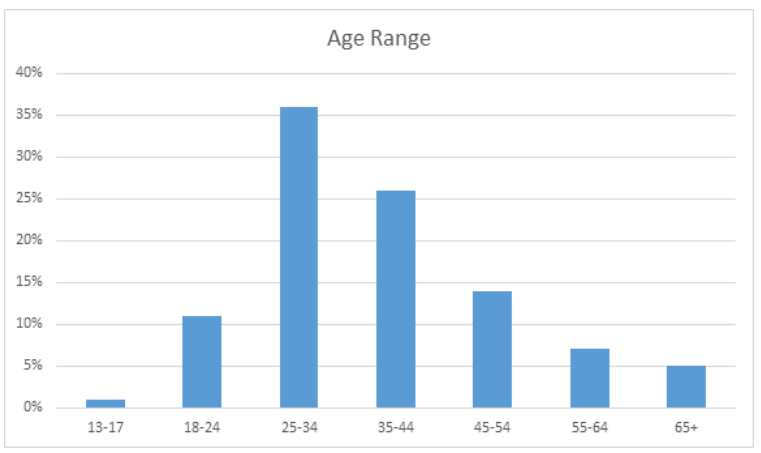

Figure 3: Age range of followers

6.2.1. Engagement The posts in the last year with the most likes and comments, as pictured in Figure 4, featured predominantly images showcasing manuscript books (top left), brightly colored spines (top center) or marbled edges (left center), marginalia (bottom left), old parchment bindings (bottom right), and fore-edge paintings. Fore-edge paintings are hidden from view until pages are fanned revealing the image. The corresponding hashtag, \#ForeedgeFriday has over 1,800 posts. Jordan_Library specific posts are tracked with the hashtag, \#JordanForeedge (47 posts).

6.2.2. Reach The reach number is calculated by counting the number of unique accounts that have viewed a particular post. The reach metric is an estimate, with Figure 5 showing the reach over the past year. Posts that received the most engagement consequently reached the largest audience.

6.2.3. Impressions The impressions include the total number of times that a post has been seen, as in Figure 6 . Like reach, posts with more engagement had more impressions corresponding with Instagram's algorithm. The more people who like a post the more it will be seen. 


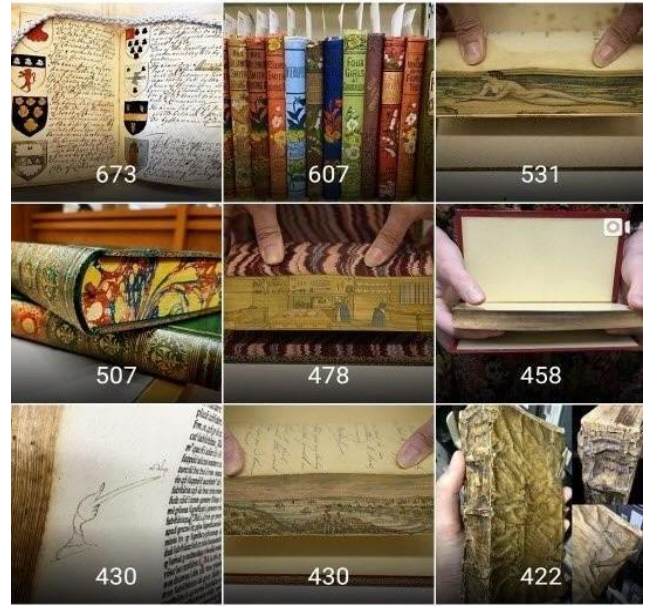

Figure 4: Top engagement posts

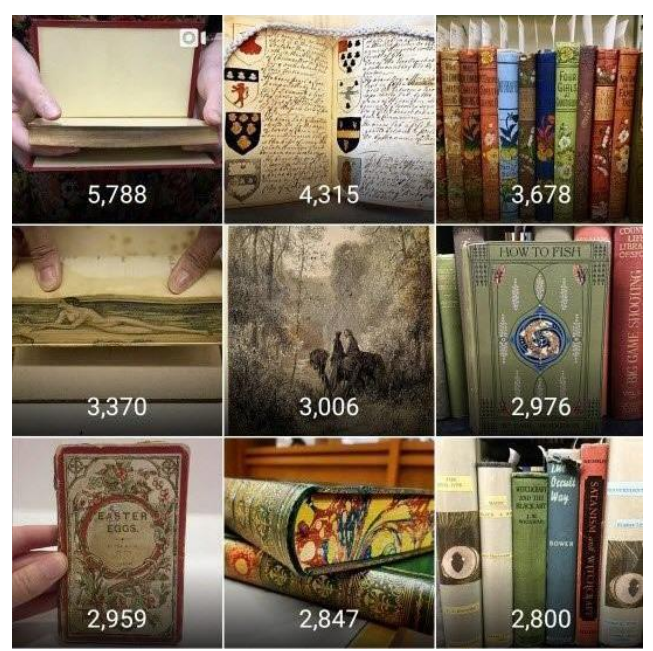

Figure 5: Top reach posts

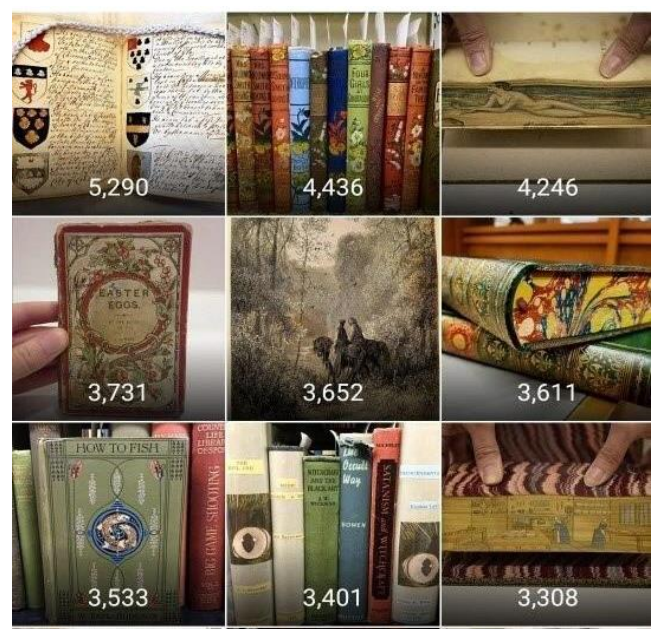

Figure 6: Top impressions posts

\subsection{Participation in \#IGLibraries hashtag challenges}

Engagement in a hashtag challenge signals inclusion in the Libraries of Instagram community, adopting a major convention of the community, and this library's membership in that community by taking on a moderator role.

Jordan_Library first sponsored an IGLibraries hashtag challenge in December 2016, using the hashtag \#LibraryWonderland. The challenge was repeated in 2017 (sponsored again by Jordan_Library) and in 2018 (sponsored by @iglibraries).

One of the goals with this challenge was to be open to anyone who wanted to participate. To prepare for the challenge we had to select a hashtag to gather all the posts. The aim was to be inclusive of all libraries, especially since some of the more active libraries are in Las Vegas and Florida where winter wonderland is not such an obvious theme. \#LibraryWonderland captured the winter idea, but stayed broad.

To direct and promote the challenge we created a small infographic with the tag and post ideas listed. We shared this on our feed, in the direct message with other rare book libraries, and it was also posted by the account @iglibraries. In that month, 438 posts were created using the hashtag. Rare book libraries, public libraries, book sellers, book collectors, and book lovers all participated. We were pleased to see such diversity among the accounts because it meant that we had reached all members of the rare book community.

However, supporting the effort and building community is not as simple as suggesting a hashtag and then watching the posts come in each Wednesday. As the sponsoring institution, we went through each post and at a minimum liked the post, but often left comments too. (Figure 7) Having posts validated by the people who propose a challenge contributes to the positive atmosphere of both the community and the platform and it encourages people to keep participating in the monthly challenges.

As a result of taking on the moderator role of the community for December 2016, we saw a significant increase in our number of followers jumping from 2,666 in November to 3,071 in December leading up to the challenge. Our numbers continued to rise reaching 3,398 in January, then increasing by over 400 more to reach 3,812 in February. Our average number of likes saw a significant uptick as well, as demonstrated in Figure 8. 


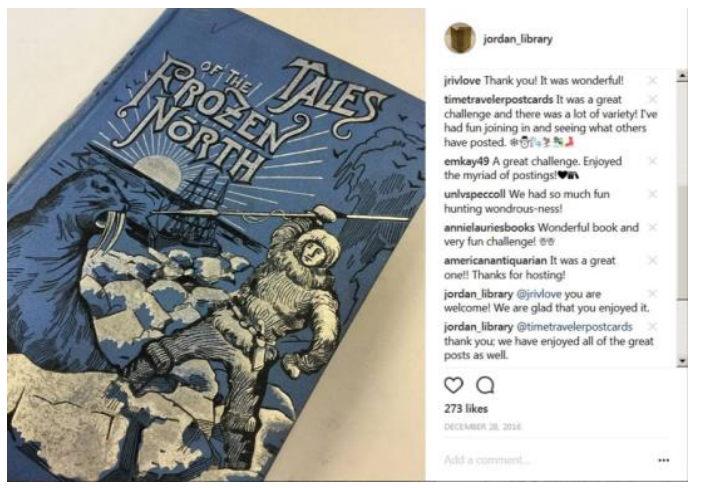

Figure 7: December 26, 2016

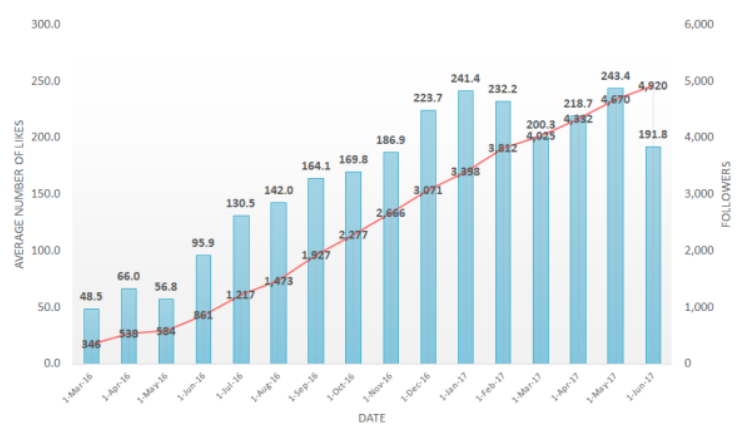

Figure 8: Average number of likes with follower count by month from March 2016 to June 2017

The growth over those few short months is indicative of how participating in the IGLibraries community helped increase the account's visibility. With more followers certainly more people are aware of the collections, the library has also connected with more people in the community, and the library signalled its commitment to the success of the community.

\section{Conclusion}

The study of \#LibrariesOfInstragram provides an interesting insight into how rare book and special collections institutions have leveraged the value of images into building a community and promoting educational and curatorial goals. Prior to 2016, when W. D. Jordan Rare Books and Special Collections initiated its Instagram account and began participating with \#LibrariesOfInstagram, it was only known to a handful of other institutions and individuals, largely within the Canadian academic milieu. Within months, the Instagrammers behind the Jordan_Library feed were part of an international community, meeting at the Rare Books and Manuscript Section conference in Miami, Florida to discuss best practices. Engagement with a larger number of followers furthers the ultimate goals of education, research and increased support for the curatorial mission of cultural heritage institutions.

The activity on the account, represented by the number of likes the content generates, is a critical metric used to measure engagement by the community. By hiding this key metric, albeit to reduce attention to socially unacceptable sites, it has made it difficult for Canadian educational communities to measure engagement by the community.

To be sure, one case study is limited in its applicability to a broader scope, but the results are representative of and demonstrative of practices within the overall rare book community. While further research can provide more insight into uses of Instagram, the case so far shows the potential for the dynamic and networked nature of the platform to support user engagement and institutional community development.

\section{References}

[1] Bregman, A. M. Emblemata: The emblem books of Andrea Alciato. Bird \& Bull Press, Newtown, PA, 2005. http://hdl.handle.net/2142/14822

[2] Buckeurt, K. "Do you like this? How Instagram Hiding Likes Could Impact Your Social Media Use", The Canadian Broadcasting Corporation, May 4, 2019, https://www.cbc.ca/news/canada/kitchenerwaterloo/instagram-hiding-likes-1.5122381, accessed June 14,2019

[3] Budhathoki, N.R. and Haythornthwaite, C., "Motivation for open collaboration: Crowd and community models and the case of OpenStreetMap", American Behavioral Scientist, 57(5), 2013, 548-575.

[4] Dean J. and E. Grover, "Social Media as Entreé into Special Collections Reference Works", RBM: A Journal of Rare Books, Manuscripts, and Cultural Heritage, 18(1), 2017, pp. 37-43.

[5] Dean, J. W., "Special Collections Instagram Syllabus", Jason W. Dean, January 30, 2017, https://medium.com/@jason_w_dean/special-collectionsinstagram-syllabus-2f3810323b4f, accessed June 14, 2019.

[6] Dias De Fazio, D. "Libraries of Instagram", Primary Source News \& Notes: RBMS Instruction and Outreach Committee Newsletter. Sept. 19, 2018, https://us18.campaignarchive.com/?u=93a27beb43e1d46ef40074d43\&id=e87a4f $480 \mathrm{~d}$

[7] Garner, A., Goldberg, J., and Pou, R. (2016). "Collaborative Social Media Campaigns and Special Collections: A Case Study on \#ColorOurCollections", RBM: A Journal of Rare Books, Manuscripts, and Cultural Heritage, 17(2), 2016, p. 100-117.

[8] Gilman, E. P. "Word and image in Quarles' Emblemes" Critical Inquiry, vol. 6, no. 3 (Spring 1980), 385-410.

[9] Gruzd, A. and Haythornthwaite, C., "Enabling community through social media", Journal of Medical Internet Research. 15(10), 2013, e248. 
http://www.jmir.org/2013/10/e248/. DOI:

10.2196/jmir.2796 PMID: 24176835

[10] Haythornthwaite, C., "Strong, weak and latent ties and the impact of new media", The Information Society, 18(5), 2002, 385-401.

[11] Haythornthwaite, C., "Social networks and Internet connectivity effects. Information, Communication \& Society, 8(2), 2005, 125-147.

[12] Haythornthwaite, C., "Crowds and communities: Light and heavyweight models of peer production", Proceedings of the $42^{\text {nd }}$ Hawaii International Conference on System Sciences, Los Alamitos, CA, IEEE Computer Society, 2009. doi:10.1109/HICSS.2009.650

[13] Hou, J. "Integrating Community and Relationship Building Into Universities' Social Media Marketing: Implications from a Case Study", in B. Rishi, S. and Bandyopadhyay, eds., Contemporary Issues in Social Media Marketing, London, Routledge, 2018, p. 40-55.

[14] IGLibraries, "\#LibrariesOfInstagram: HashtagLibrary”, No date, https://docs.google.com/spreadsheets/d/1SLsenBWOGnTw 7W85VnMSSk1_7UxTLfyoqAFdu7WRIBo/edit\#gid=1348 570740 accessed June 14, 2019.

[15] Info Center, "Connecting You With Friends, Family and Interests on Instagram”, Info Center, 2019, https://instagram-press.com/blog/2019/04/30/connectingyou-with-friends-family-and-interests-on-instagram/, April 30, 2019.

[16] Info Center, "Creating a More Accessible Instagram,” Info Centre, May 17, 2019, https://instagrampress.com/blog/2018/11/28/creating-a-more-accessibleinstagram/.

[17] Info Center, "Our Story", Instagram, 2019, https://instagram-press.com/our-story/, accessed June 6, 2019.

[18] Info Center, "See the Moments You Care About First", Info Centre, https://instagrampress.com/blog/2016/03/15/see-the-moments-you-careabout-first/, (May 17, 2019).

[19] Instagram, "How do I use hashtags on Instagram?”, Help Center, May 9, 2019 https://help.instagram.com/351460621611097, accessed June 14, 2019.

[20] "Instagram", Special Collections + Social Media Wiki, no date, http://specialcollectionssocialmedia.pbworks.com/w/page/6 7443360/Instagram, accessed June 14, 2019

[21] Jones, M. J., and M. Harvey, "Library 2.0: The Effectiveness of Social Media as a Marketing Tool for Libraries in Educational Institutions", Journal of Librarianship and Information Science, 51(1), 2019, pp. 319.

[22] Laestadius, L., "Instagram", in The SAGE Handbook of Social Media Research Methods, ed. Luke Sloan and Anabel Quan-Haase, London, SAGE, 2017, pp. 575-592.

[23] Lave, J. and Wenger, E., Situated learning: legitimate peripheral participation. Cambridge, UK: Cambridge University Press, 1991.

[24] Loren, T. “Instagram is Hiding Likes: Here's Everything You Need to Know", Later, https://later.com/blog/hidden-likes-instagram/, (May 17, 2019).

[25] Macallum, I., "Use of Social Media by the Library Current Practices and Future Opportunities: A White Paper from Taylor \& Francis", The Australian Library Journal, 64(2), 2015, https://doi.org/10.1080/00049670.2015.1040364.

[26] Manning, J., The Emblem, Reaktion Books, London, 2002.

[27] NY Academy of Medicine, “\#ColorOurCollections", NYAM, Feb. 8, 2019, https://library.nyam.org/colorourcollections/participatinginstitutions/, accessed June 14, 2019.

[28] Panko, B., "A Decade Ago, the Hashtag Reshaped the Internet", Smithsonian, https://www.smithsonianmag.com/smart-news/decade-agohashtag-reshaped-internet-180964605/, May 17, 2019.

[29] Preece, J., Nonnecke, B. and Andrews, D., "The top five reasons for lurking: improving community experiences for everyone", Computers in Human Behavior, 20(2), 2004, 201-223.

[30] Rainie, L. and Wellman, B. (2012). Networked: The new social network operating system. Cambridge, MA, MIT Press, 2012.

[31] Robin, C.D., "Using Instagram for Your Library: 9 Strategies", Emerging Tech in Libraries, September 30, 2013.

https://emerging.commons.gc.cuny.edu/2013/09/usinginstagram-library/, accessed June 13, 2019.

[32] Serafinelli, E., Digital Life on Instagram: New Social Communication of Photography, Emerald Publishing, Bingley, UK, 2018.

[33] Shulman, J., J. Yep, and D. Tome, "Leveraging the Power of a Twitter Network for Library Promotion", The Journal of Academic Librarianship, 41(2), 2015, pp. 178-185.

[34] Solomon, L., The Librarian's Nitty-Gritty Guide to Social Media, ALA Editions, Chicago, 2013.

[35] Solomon, L., The Librarian's Nitty-Gritty Guide to Content Marketing, ALA Editions, Chicago, 2016.

[36] Sun, Na, Rau, P.P. and Ma, L., "Understanding lurkers in online communities: A literature review", Computers in Human Behavior, 38, 2014, 110-117. https://doi.org/10.1016/j.chb.2014.05.022

[37] Thiemer, K. M., Web 2.0 and Strategies for Archives and Local History Collection, Neil-Schuman, NY, 2010

[38] Wenger, E., Communities of practice: learning, meaning, and identity. Cambridge, UK: Cambridge University Press, 1998.

[39] Williamson, F., S. Vieira, and J. Williamson, "Marketing Finding Aids on Social Media: What Worked and What Didn't Work", The American Archivist, 78(2), 2015, pp. 488-513. 